\title{
Methods of rapid diagnosis for the etiology of meningitis in adults
}

Infectious meningitis may be due to bacterial, mycobacterial, fungal or viral agents. Diagnosis of meningitis must take into account numerous items of patient history and symptomatology along with regional epidemiology and basic cerebrospinal fluid testing (protein, etc.) to allow the clinician to stratify the likelihood of etiology possibilities and rationally select additional diagnostic tests. Culture is the mainstay for diagnosis in many cases, but technology is evolving to provide more rapid, reliable diagnosis. The cryptococcal antigen lateral flow assay (Immuno-Mycologics) has revolutionized diagnosis of cryptococcosis and automated nucleic acid amplification assays hold promise for improving diagnosis of bacterial and mycobacterial meningitis. This review will focus on a holistic approach to diagnosis of meningitis as well as recent technological advances.

Keywords: aseptic meningitis $\bullet$ bacterial meningitis $\bullet$ Cryptococcus meningitis $\bullet$ diagnosis - diagnostic tests $\bullet$ tuberculosis meningitis

Meningitis is a syndrome classically characterized by some combination of neck stiffness, headache, fever and altered mental status; other symptoms including nausea, vomiting and photophobia are frequently observed as well $[1,2]$. Meningitis may be due to bacteria, mycobacteria (e.g., Mycobacterium tuberculosis), fungi (predominantly Cryptococcus neoformans), viruses, parasites (e.g., cysticercosis due to Taenia solium), rickettsia or Treponema (e.g., syphilis) or noninfectious causes such as malignancy or rheumatologic conditions [2]. This review will focus on bacterial, mycobacterial, fungal and viral meningitis diagnostics. Prompt diagnosis is crucial in meningitis care as many causes of meningitis carry a high mortality, especially with any delay in diagnosis [3].

Adult mortality may vary widely according to cause and setting with rates of 3-30\% for bacterial meningitis depending on the organism [4,5]. Aseptic meningitis (usually referring to viral meningitis but also encompassing other 'culture-negative' types of meningitis) is generally considered to a benign, self-limited disease with low mortality [6], of note this does not include encephalitis due to herpes simplex virus (HSV) where mortality may be up to $70 \%$ without treatment, and still as high as $28 \%$ with acyclovir therapy [7]. Tuberculous meningitis (TBM) and cryptococcal meningitis carry high mortality rates of $>50 \%$ in routine care $[8,9]$.

Additional historical information such as duration of symptoms, sexual history, vaccination history, drug use history, personal history of TB, travel history and country of origin are extremely useful in considering the possible causes of meningitis $[2,10]$. Though helpful in narrowing the etiologic possibilities, symptoms and history alone are unreliable in terms of their ability to determine whether or not meningitis is present; much less its etiology [2]. One must combine this information with a good understanding of the basic epidemiology pertaining to the situation - knowing what types of meningitis might be common given a particular patient's background informs diagnostic testing. This information, together, allows the provider to
Nathan C Bahr*,1,2 \& David R Boulware ${ }^{1,2}$ 'Division of Infectious Disease \& International Medicine, Department of Medicine, University of Minnesota, Minneapolis, MN 55455, USA ${ }^{2}$ Center for Infectious Diseases \& Microbiology Translational Research, University of Minnesota, Minneapolis, MN 55455, USA

*Author for correspondence:

Tel.: +1 6126249996

Fax: +16126254410

bahrx026@umn.edu 
efficiently order diagnostic testing to attempt to make a definitive diagnosis.

\section{Epidemiology}

The most common bacterial etiologies of meningitis are Streptococcus pneumoniae, Neisseria meningitidis, Haemophilus influenzae, Listeria monocytogenes and (in infants) Group B Streptococcus [5].

Streptococcus pneumoniae is the most common bacterial cause of meningitis worldwide among all ages, accounting for approximately $70 \%$ of isolates in US adults. $N$. meningitidis is second most common at approximately $11.5 \%$ of adult cases [4]. The incidence has decreased of both pneumococcal and meningococcal meningitis with vaccination in the US and England [11-13]. In South Africa, implementation of the 7-valent and then 13-valent pneumococcal conjugate vaccine has resulted in a $62 \%$ decline in invasive pneumococcal disease among children $<5$ years of age between 2009 and 2012 [14]. Meningitis accounts for $43 \%$ of invasive pneumococcal disease in South Africa [14]. Yet, the overall incidence of bacterial meningitis in low- and middle-income countries overall is greater than in high-income countries. For example, one systematic review found incidence of $S$. pneumoniae ranging from 5.8 to 12 cases per 100,000 adults (stratified by age group) in four countries in the African 'meningitis belt' as compared with a rate of 0.81 cases per 100,000 adults in the USA [4,15]. In South Africa during 2012, the incidence of confirmed pneumococcal meningitis was 2.6 per 100,000 total population [14]. Epidemics due to either bacteria to may occur [16] but are noted more frequently with $N$. meningitidis where rates vary widely by region and may be historically as high as 1000 cases per 100,000 adults in the meningitis-belt outbreaks as compared with $0.27-1.43$ cases per 100,000 adults by age group in the USA and 0.31 per 100,000 total population in South Africa [11,14,17-18]. However, the landscape of meningococcal disease has drastically changed since the implementation in 2010 of a new meningococcal A conjugate vaccine (MenAfriVac). This meningococcal serotype $A$ vaccine in the 'meningitis belt' of Africa has drastically reduced rates of disease [16,19]. Between 2010 and 2012, the GAVI alliance vaccinated $>100$ million people in the meningitis belt, dropping the confirmed cases of meningitis A from a collective 1512 in 2009 in Burkina Faso, Mali and Niger to zero cases in 2012. For the MenAfriVac vaccine, the use of controlled temperature chain (at $\leq 40^{\circ} \mathrm{C}$ for $\leq 4$ days), instead of traditional cold chain $\left(2-8^{\circ} \mathrm{C}\right)$, should likely greatly accelerate deployment to even remote regions [20].

Haemophilus influenzae serotype b (Hib) was a major cause of meningitis in children until an effective vaccine was developed [4,5]. Now, most $H$. influenzae meningitis cases occur in adults ( $\sim 6 \%$ of US cases of bacterial meningitis) due to nontypeable strains $[4,5]$. The rarity of $H$. influenzae is likely related to herd immunity due to childhood vaccination [21]. As of 2013, national immunization programs include the Hib vaccine in 189 countries with approximately $50 \%$ global coverage of children. Notable exceptions include China, Thailand, South Korea and South Sudan. The GAVI alliance has been instrumental in implementation of the pentavalent vaccine, which protects against diphtheria-tetanus-pertussis, hepatitis B and Hib.

Group B streptococcus (Streptococcus agalactiae) and L. monocytogenes are responsible for 7 and $4 \%$, respectively, of adult cases of bacterial meningitis in the US [4]. Vaccination is not available for either pathogen. Screening and treatment of colonized pregnant women in the US for group B streptococcus has led to a large decrease in neonatal cases $[4,5]$ though this decrease has not been noted in adults where cases may have actually increased $[22,23]$. Little information is available about either cause of adult meningitis in resource-poor settings.

Tuberculosis is a rare condition in many highincome countries (35 cases per 100,000 persons in the WHO Americas region) but higher rates in regions, particularly those with high rates of HIV infection such as the WHO African (293 cases per 100,000) and south-east Asian regions (271 cases per 100,000) [24]. Among 8.7 million estimated new cases of tuberculosis, the WHO projected $13 \%$ of these were associated with HIV infection - of those approximately $80 \%$ occurred in Africa [24]. Among the reported approximately 6.2 million reported (as opposed to estimated) cases in 2011, 800,000 were classified as isolated extrapulmonary TB (which includes TBM among many other forms) [24], Thwaites estimates approximately $1 \%$ of tuberculosis is TBM [8]. Individuals with TB and HIV co-infection have a higher rate of TBM than persons without HIV $[8,25]$ as evidenced by one Spanish study where TBM was found in $10 \%(45 / 455)$ of TB patients with HIV and only 2\% (38/1750) of TB cases without HIV [26]. In two South African studies (high HIV and TB prevalence) $28-44 \%$ of patients with meningitis had microbiologically confirmed TBM, $88-94 \%$ of those patients with TBM were HIV coinfected $[10,27]$. A meta-analyses including 15 studies in African countries with varying prevalence of HIV and TB found $5.2-28 \%$ of meningitis cases were due to TBM, with $55-88 \%$ of those cases being in patients with HIV (data not available for all studies) [28].

Cryptococcosis is primarily a disease seen in persons with advanced HIV although cases of Cryptococcus gattii and neoformans occur in HIV-negative patients (with or without immunosuppression) [29,30]. Crypto- 
Table 1. Comparison of common etiologies of meningitis based on immune status.

\begin{tabular}{|c|c|}
\hline Severe immune suppression & Not immune suppressed \\
\hline Cryptococcal meningitis $^{\dagger}$ & Aseptic meningitis \\
\hline Tuberculosis meningitis $^{\dagger}$ & Bacterial meningitis \\
\hline Bacterial meningitis & Tuberculosis meningitis \\
\hline \multicolumn{2}{|l|}{ Aseptic meningitis } \\
\hline \multicolumn{2}{|c|}{$\begin{array}{l}\text { The table is listed in order of most common to least common causes of meningitis. The order of causes in the immunosuppressed column is } \\
\text { based on persons living with AIDS but is relevant to other causes of T-cell immunosuppression. } \\
\text { 'Immune reconstitution inflammatory syndrome should be strongly considered in HIV-infected persons newly initiating antiretroviral therapy } \\
\text { or in persons with iatrogenic immunosuppression discontinuing immunosuppression. }\end{array}$} \\
\hline
\end{tabular}

coccus is the most common cause of meningitis in much of sub-Saharan Africa [31] where $75 \%$ of the estimated global burden of cryptococcosis occurs [32]. In settings with high rates of HIV, Cryptococcus is a significant cause of morbidity and mortality. The same two South African studies referenced earlier showed 45-63\% of meningitis as being due to $C$. neoformans $[10,27]$, while in one Malawian study the proportion was 43\% [33]. 720,000 cases are estimated to occur per year in subSaharan Africa and a significant number of cases occur in south/southeast Asia and Latin America (120,000 and 54,400, respectively) [32]. In South Africa in 2012, the incidence rate of cryptococcal meningitis was 119 cases per 100,000 populations of HIV-infected persons with an in-hospital fatality rate of $32 \%$ [34]. With the substantial expansion of ART access in South Africa, the incidence rate has declined by only $10 \%$ from 2010 to 2012 [14,34].

Other causes of fungal meningitis that are more rare include Coccidioides immitis, Blastomyces dermatitidis, Histoplasma capsulatum, Candida spp., Aspergillus spp., Zygomycetes [25], and the well-documented 2012 US outbreak of Exserohilum rostratum meningitis related to contaminated corticosteroid injections [35]. Of the endemic fungi, CNS involvement is generally rare (2\%) and symptoms prolonged (i.e., months) [36-38]. This duration of progressive symptoms is an important detail to direct targeted testing.

The term aseptic meningitis encompasses vast etiologic possibilities, the majority of which are assumed to be viral in etiology. Enteroviruses cause $70-95 \%$ of those cases of aseptic meningitis in which an infectious etiology is found [39] with HSV and varicella zoster virus (VZV) being less common [40]. Yet, HSV and VZV are particularly important pathogens as acyclovir treatment exists. Nonviral causes include tick-borne illness such as Lyme disease, medications, rheumatologic disease and infections that more often are culture positive (e.g., tuberculosis, Cryptococcus) [41]. Local endemic diseases may shift proportions of etiologic agents of aseptic meningitis. For instance, in a dengue fever endemic region, $50 \%$ of cases were due to enteroviruses, 15\% HSV, 15\% unknown etiology, 10\% dengue virus and $10 \%$ cytomegalovirus (CMV) [42].

\section{The host}

The immune status of the patient presenting with meningitis is extremely important in narrowing or expanding the differential diagnosis. Table 1 shows a comparison of common etiologies of meningitis with and without immune compromise. The most obvious example of immune suppression is HIV infection. In patients living with AIDS, other CNS pathologies (e.g., CNS lymphoma, toxoplasmosis, etc.) should be on the differential; however, these conditions generally present differently than meningitis, most often presenting with focal neurologic deficits [25]. Clearly, meningitis due to Cryptococcus or $M$. tuberculosis should be considered very likely in a patient with advanced HIV disease $[10,27]$. In a patient with advanced HIV, but less severe immune suppression (e.g., CD4 ${ }^{+}$T-cell count $>100$ cells $/ \mu \mathrm{l})$, Cryptococcus becomes less likely, though still possible $[25,43]$. In HIV-infected patients, TBM frequently presents in patients with $\mathrm{CD} 4^{+}$counts $<100$ cells/ $\mu$ [ [44], and although TBM may occur with any $\mathrm{CD}^{+}$count, CD $4>200$ cells $/ \mu$ is less common [10,26-27]. TBM patients with HIV have a higher mortality rate than do those TBM patients without HIV [8] and in fact, risk of death from TBM is inverse to the $\mathrm{CD}^{+}$count $[10]$, making prompt diagnosis all the more important.

Bacterial meningitis is also frequent in HIV-infected persons. In a study of 233 Malawian HIV-infected patients presenting with meningitis, 28 (12\%) cases were caused by bacteria with a median $\mathrm{CD} 4^{+}$count of 119 cells/ $\mu$ l (interquartile range 56-457 cells/ $\mu \mathrm{l}$ ) [33], a study of South African patients (94\% HIV+) found a similar proportion $(8 \%)$ of meningitis cases were due to bacteria though the mean CD4+ count was 287 cells/ $\mu \mathrm{l}$ [27]. In a study of $215 \mathrm{HIV}$-positive patients presenting with meningitis in the Central African Republic $31 \%$ had bacterial meningitis [45]. Of these 66 cases of bacterial meningitis, $22(33 \%)$ were due to $S$. pneumoniae, nine $(14 \%)$ due to $N$. meningitidis, six due to 
Gram-negative rods and one each of Staphylococcus aureus and Listeria each - with 24 cases were presumed bacterial meningitis based on cell count and chemistry but culture negative [45]. Finally, in a Spanish study among $25 \mathrm{HIV}$-infected patients with microbiologically confirmed bacterial meningitis, etiologies were S. pneumoniae (60\%), N. meningitidis (8\%), Staphylococcus aureus (8\%), Listeria (12\%) and various Gramnegative bacteria (12\%), respectively [46]. Although the proportion of cases attributed to each cause varies by region, $S$. pneumoniae is uniformly the most common bacterial cause of meningitis in HIV-infected persons. Further, patients with HIV have a six- to 324-times higher risk of invasive pneumococcal disease than patients without HIV, even on ART the risk is 35-times higher than the persons without HIV [5]. The increased risk of bacterial meningitis is thought to be due to disturbed humoral immunity [46]. However, the increased risk of bacterial meningitis compared with the general population needs to be put in the context of the incidence of Cryptococcal meningitis in an HIV-infected population, whereby Cryptococcus is more common than all causes of bacterial meningitis combined $[27,47]$. Figure 1 shows an algorithm for diagnosis of meningitis in patients with severe immune suppression with this context in mind.

Equally important in patients with HIV infection is considering whether or not the patient is receiving antiretroviral therapy (ART). If the patient has initiated ART within the prior 3 months, immune reconstitution inflammatory syndrome (IRIS) should be considered. IRIS is the worsening of symptoms due to inflammation caused by immune activation in patients previously treated for an opportunistic infection (paradoxical IRIS) or an exaggerated presentation of a previously unrecognized opportunistic infection upon starting ART (unmasking IRIS) [48]. Paradoxical CNS IRIS occurs in $20-30 \%$ of cryptococcosis patients who survive to receive ART and up to $47 \%$ TBM patients who are subsequently started on ART [48]. Thus, in a patient who has recently started ART with worsening CNS symptoms and a recent history of CNS infection, paradoxical IRIS should be strongly considered along with treatment failure/relapse due to drug resistance. In patients with CM, IRIS is seen more commonly in patients with $\mathrm{CD}^{+}$counts $<100$ cells $/ \mu$ l, less evidence of cerebrospinal fluid (CSF) inflammation (e.g., low WBC count and normal protein), and greater organism burden (evidenced by high $\mathrm{CrAg}$ titer and/or quantitative culture) at baseline [48]. In patients with TBM predictors of IRIS include higher CSF neutrophil counts and increased bacillary load at baseline [48].

The most common unmasking IRIS etiology due to ART that occurs with CNS manifestations is
Cryptococcus. The prevalence of subclinical Cryptococcal antigenemia (i.e., serum or plasma cryptococcal antigen $[\mathrm{CrAg}]$ positivity) ranges from 4 to $12 \%$ in persons with CD4 counts $<100$ cells/ $\mu$ l, with lower prevalence above this threshold [43,48-49]. Unmasking cryptococcal manifestations can be diverse extending beyond meningitis to include parenchymal disease with cryptococcomas and unusual neurologic or cerebellar deficits. Cryptococcoma(s) can appear identical as toxoplasmosis with ring-enhancing lesions on head computed tomography (CT). In contrast, unmasking of toxoplasmosis among persons receiving trimethoprim-sulfamethoxazole prophylaxis is exceedingly rare. Unmasking of TBM is also possible, and these persons typically often have disseminated $\mathrm{TB}$ outside of the CNS as well [48]. For any unmasking IRIS event occurring within 3-4 months of starting ART in an HIV-infected person with AIDS, CrAg testing of blood is an essential first diagnostic step.

Asplenic patients are at high risk for bacterial meningitis, in particular S. pneumoniae, $N$. meningitidis and $H$. influenzae, because they lose the splenic macrophages that phagocytize pathogens [50]. Vaccination against these pathogens is recommended for asplenic patients [50]. A cohort study showed that 24 out of 965 patients with microbiologically proven bacterial meningitis were asplenic; all 24 of these patients grew S. pneumoniae [51].

Diabetes mellitus, alcoholism, chemotherapy, medications and cancers also effect on the types of meningitis one might encounter as they cause immune dysfunction [5]. Bacterial meningitis remains a significant concern with some causes occurring more frequently in immunosuppressed patients than normal hosts. B-cell dysfunction with humoral immunoglobulin deficiency is a risk factor for encapsulated organisms, such as S. pneumoniae and H. influenzae [52]. In a case series from France, 38\% of persons with invasive pneumococcus or Hemophilus had an immunoglobulin abnormality [52]. Additionally with group B streptococcal meningitis in adults, a literature review reported immunosuppression in $42 \%$ of 64 adults [53]; whereas in a case series of Listeria meningitis all 30 patients had immunosuppression or were $>50$ years of age [54]. Although these two organisms are more common in immunosuppressed populations than in the general population, typical organisms such as $S$. pneumoniae and $N$. meningitidis should still be considered more likely culprits [55]. Often, the immunodeficiency will not be discovered until after the infection occurs. TBM is also an important consideration with non-HIVrelated immune compromise; particularly in association with TNF- $\alpha$ inhibitor use [56]. TBM should also be considered in patients with hematologic malignan- 


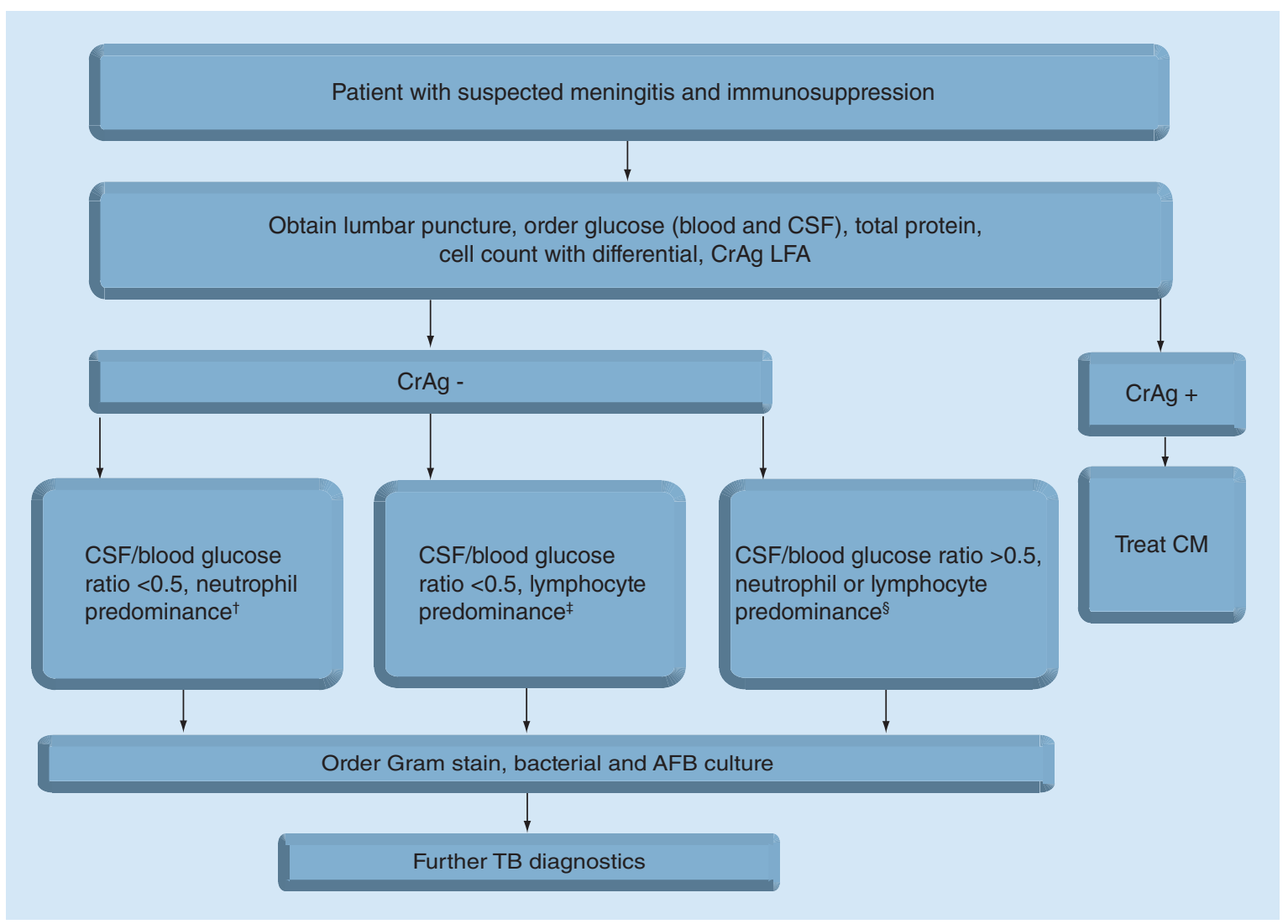

Figure 1. Algorithm for diagnosis of meningitis in patients with known immune compromise.

${ }^{+}$Most likely bacterial meningitis, institute empiric antibiotics after lumbar puncture (or before if the patient is unstable). If Gram stain and culture are negative may consider 16s rRNA PCR (if available).

${ }^{\ddagger}$ Most likely tuberculous meningitis. If acid fast bacilli smear unremarkable and duration of symptoms correlate strongly consider empiric treatment and/or nucleic acid amplification tests, ideally testing a large volume (>5 ml) of centrifuged cerebrospinal fluid.

${ }^{\S}$ Most likely aseptic meningitis. Consider nucleic acid amplification tests for viral pathogens if serum inflammatory biomarkers (e.g., C-reactive protein, procalcitonin) are minimally elevated or normal.

AFB: Acid-fast bacilli; CM: Cryptococcal meningitis; CrAg: Cryptococcal antigen; CSF: Cerebrospinal fluid;

LFA: Lateral flow immunochromatographic assay.

cies, those who undergo solid organ or bone marrow transplant or other patients with immune compromise who have untreated, latent TB infection [57,58]. Cryptococcus is a significant concern in immune compromised populations as cases have been described in patients receiving chemotherapy, high-dose corticosteroids, biologic agents such as infliximab, immunosuppressive drugs such as azathioprine, as well as patients with both hematologic and nonhematologic malignancies, diabetes mellitus, alcoholism and/or liver cirrhosis and solid organ transplant [48,59-61]. Viral etiologies of meningitis in non-HIV-infected persons with immune compromise include human herpes virus 6 (particularly in bone marrow transplant patients), HSV, VZV, CMV, Epstein-Barr virus, JC virus (associated with progressive multifocal leukoencephalopathy) and adenovirus [62]. Additional considerations that act as defects in host defense are recent neurosurgical history or shunt placement - in these cases nosocomial organ- isms such as $S$. aureus, coagulase-negative Staphylococcus species, Acinetobacter and Pseudomonas aeruginosa are much more common [25].

Incidence of meningitis in the 'normal host' is described in some detail above and Figure 2 provides an algorithm for diagnosis in these patients. In short, $70 \%$ of bacterial meningitis is due to $S$. pneumoniae [51], although bacterial meningitis overall is still a minority of etiologies [1,24]. Aseptic viral etiologies predominate in nonimmune compromised populations. Cryptococcus is much less common in these patients than in persons with severe immune compromise [30]. Other causes of fungal meningitis are also rare in normal hosts though the outbreak of meningitis due to Exserohilum rostratum is a notable exception [35]. In non-HIV populations, TBM typically occurs at the extremes of age (i.e., infants, elderly); however, TBM can occur in non-HIV-infected adults, but likely at approximately 100 -fold less frequently than among HIV-infected per- 
sons, extrapolated from HIV prevalence rates in recent diagnostic studies [63,64]. Aseptic meningitis is the most common cause of meningitis in the patient with a normal immune system and thankfully, mortality is quite low [6]. Thus, it is important to rule out conditions with higher mortality such as bacterial, cryptococcal and TB meningitis when the history and epidemiology make these conditions possible diagnoses. In any adult with meningitis, HIV status should be checked.

\section{Duration of symptoms}

One additional way to narrow the possible etiologies in a patient with meningitis is by the duration of symptoms. Generally, bacterial meningitis presents much more acutely than do either TBM or fungal meningitis, which are subacute in onset. Viral aseptic meningitis duration of symptoms may vary. In a 2002 study in Vietnam, Thwaites et al. observed a mean duration of illness at TBM presentation of 12 days (range: 4-34 days) compared with bacterial meningitis patients' mean duration of illness of 3 days (range: 1-11 days) [65]. A study in Turkey found a median duration of illness of 7 days in TBM and $\leq 2$ days in bacterial meningitis [3]. Although broadly these differences in duration are clear, there can be overlap and so this is by no means a single entity that can accurately predict the TBM versus bacterial meningitis. Listeria monocytogenes is an important exception to the broad characterization of rapid onset of bacterial meningitis. Approximately a third of Listeria meningitis patients have symptoms for $\geq 4$ days $[54,66]$.

Duration of viral meningitis symptoms are variable but often short, overlapping with bacterial meningitis. One French study of 18 patients with bacterial meningitis and 133 patients with aseptic meningitis found equivalent durations of symptoms median 1 day (95\% CI: $1-2$ days), and 3 days (95\% CI: 0-5 days) [67]; however, a Brazilian study of 20 patients with asep-

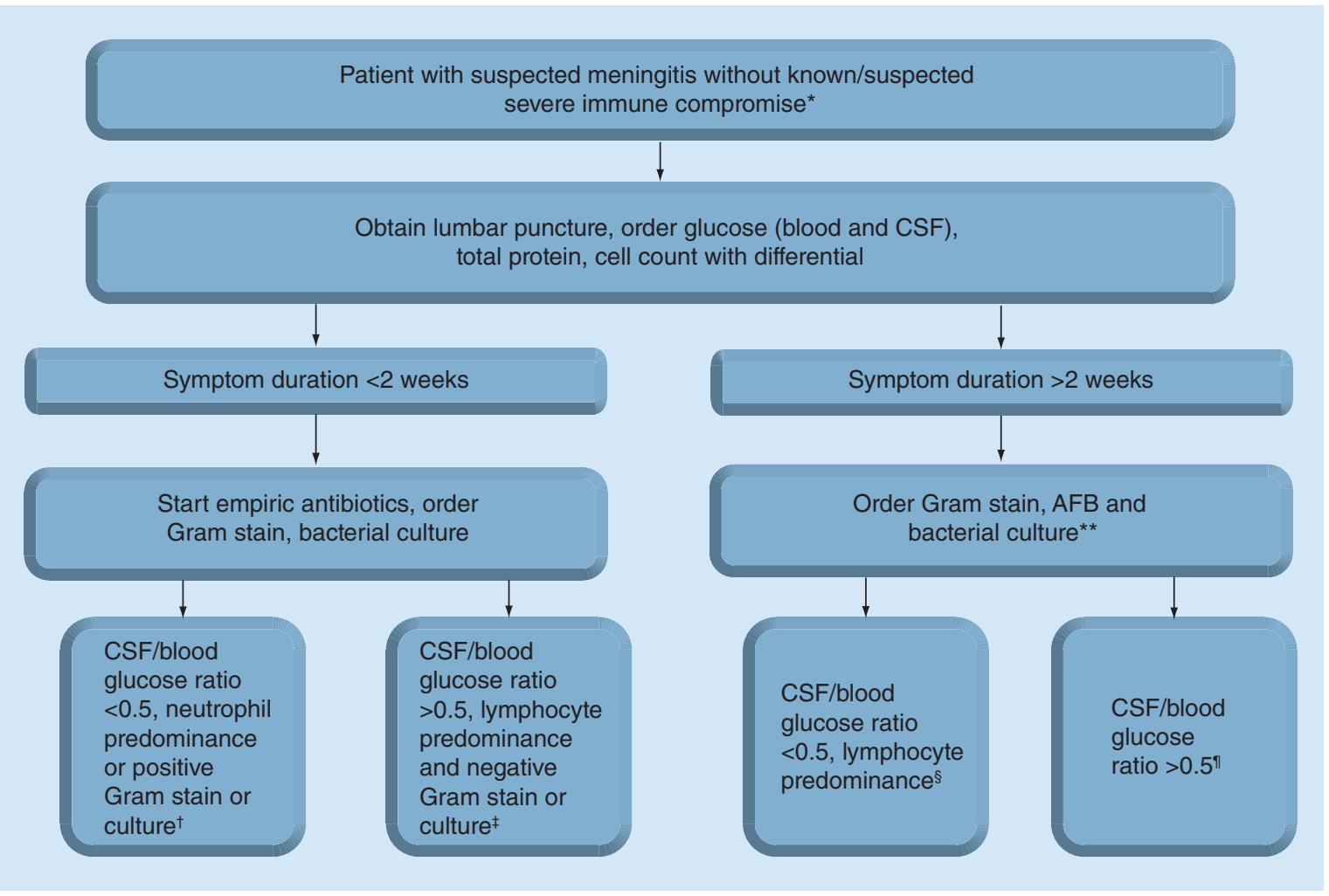

Figure 2. Algorithm for diagnosis of meningitis in patients without known immune compromise.

*If appropriate consider rapid HIV test, If HIV-infected, refer to Figure 1 algorithm.

**If mild immune compromise include cryptococcal antigen lateral flow assay, treat bacterial etiology accordingly if positive.

${ }^{\dagger}$ Likely bacterial meningitis, continue empiric antibiotics, await definitive etiology.

${ }^{\ddagger}$ Most likely aseptic meningitis, consider stopping empiric antibiotics, consider sending appropriate nucleic acid amplification tests (NAATs).

${ }^{\S}$ Most likely tuberculosis meningitis. If duration of symptoms are compatible, strongly consider empiric treatment and/or NAATs, ideally testing a large volume $(>5 \mathrm{ml}$ ) of centrifuged cerebrospinal fluid.

"Most likely aseptic meningitis, although may be tuberculosis meningiti as well. If strong clinical suspicion, consider TB NAATs.

AFB: Acid-fast bacilli; CrAg: Cryptococcal antigen; CSF: Cerebrospinal fluid. 
Table 2. Comparison of common laboratory tests in bacterial, viral, cryptococcal and tuberculosis meningitis.

\begin{tabular}{|c|c|c|c|c|}
\hline Laboratory test & $\begin{array}{l}{ }^{\dagger} \text { Bacterial } \\
\text { meningitis }\end{array}$ & $\begin{array}{l}\text { Aseptic } \\
\text { meningitis }^{\dagger}\end{array}$ & $\begin{array}{l}\text { Tuberculosis } \\
\text { meningitis }\end{array}$ & $\begin{array}{l}\text { Cryptococcal } \\
\text { meningitis }^{\ddagger}\end{array}$ \\
\hline Total protein & $245-270 \mathrm{mg} / \mathrm{dl}$ & 75 mg/dl & $191^{\dagger}-314^{\ddagger} \mathrm{mg} / \mathrm{dl}$ & 90 mg/dl \\
\hline CSF/blood glucose ratio & $0.20-0.36$ & 0.54 & $0.27^{\dagger}-0.28^{\ddagger}$ & 0.38 \\
\hline Total WBC & $\begin{array}{l}\text { Approximately } \\
500-2500 \text { cells/ } / \mu \mid\end{array}$ & 98 cells $/ \mu \mathrm{l}$ & $300^{\dagger}-375^{\ddagger}$ cells $/ \mu \mathrm{l}$ & 53 cells $/ \mu \mathrm{l}$ \\
\hline Neutrophils (\%) & $80-90 \%$ & $37 \%$ & $37 \%^{+}$ & $<20 \%$ \\
\hline $\begin{array}{l}\text { 'Median values. } \\
\text { *Mean values. } \\
\text { CSF: Cerebrospinal fluid; WBC: }\end{array}$ & nite blood cell. & & & \\
\hline
\end{tabular}

tic meningitis showed a mean duration of symptoms of 7.5 days [42]. Thus, clearly the duration of symptoms in aseptic meningitis may vary. Duration of symptoms in cryptococcal meningitis is generally at least 1 week, in the absence of HIV therapy. In two separate cohorts from Uganda and Vietnam of 434 patients with cryptococcal meningitis, the median duration of antecedent headache was approximately 14 days (interquartile range [IQR]: 7-21 days) prior to hospital presentation $[68,69]$. Unmasking cryptococcal-IRIS with HIV therapy can have a much more rapid onset, mimicking the acute onset of bacterial meningitis [49].

\section{Common diagnostic laboratory \& imaging tests}

CT and MRI may be considered as adjunctive diagnostics tests but are generally nonspecific and show meningeal enhancement [70]. Imaging may be helpful in cases of focal neurologic deficits, particularly when a tuberculoma or cryptococcoma is suspected [70]. In the absence of trauma, altered mental status or focal neurologic deficit, imaging increases healthcare costs and has minimal yield in providing a definitive diagnosis. PET has even greater expense with no ability to provide a definitive etiologic diagnosis in a person with meningitis.

Standard diagnostic testing of CSF includes: white blood cell (WBC) count with differential, total protein, and CSF/blood glucose (or CSF glucose itself), used in conjunction with patient history and epidemiology to support potential diagnoses. Total protein and WBC counts reflect inflammation in the CSF while decreased glucose CSF/blood ratio is a sign of glucose consumption by an active infection. These common laboratory tests cannot be the lone laboratory method of diagnosis and while overlap in their values among different diagnoses does occur, general trends emerge and are useful as they help the clinician to focus on particular possible diagnoses. Table 2 shows median and/or mean values for these laboratory tests stratified by condition [65,67,71-72]. Importantly, up to $40 \%$ of persons with Cryptococcus may have an unremarkable CSF WBC $<5$ cells $/ \mu$ l, which can mistakenly delay the diagnosis [73]. For other endemic fungi (e.g., histoplasmosis, blastomycosis, coccidioidomycosis), CSF typically shows lymphocytic pleocytosis with protein elevation $(\sim 80 \%)$, and a variably depressed glucose (approximately 80\%). Additionally, TBM-related and cryptococcal-related IRIS generally have high CSF protein levels and high WBC counts as IRIS is an inflammatory process $[48,73]$.

More specific technologies have been, or are under development to enable more confident diagnosis of the major etiologic agents of meningitis (Table 3). One example of a technology that could potentially be applied broadly to meningitis is that of a PCR multiplex panel. These panels allow for detection of multiple different pathogens that might cause a particular syndrome with one test - ideally in rapid, easy to use and accurate manner. Panels have successfully been trialed for use in respiratory illnesses and blood cultures [74,75], a panel developed for sepsis has been trialed in patients with meningitis [76], and another multiplex PCR panel has been developed for use in meningitis (although not yet thoroughly studied) [77]. Technologies such as multiplex PCR are exciting, but in the case of meningitis, not yet ready to aide clinicians. Below we discuss the use of specific diagnostic tests and their roles for diagnosing various causes of meningitis.

\section{Diagnostic tests for fungal meningitis}

Diagnosis of cryptococcal meningitis has been revolutionized by the development of an extremely accurate lateral flow immunochromatographic assay (LFA (Immuno-Mycologics [Immy], Norman, Oklahoma, USA) to detect CrAg. While CSF culture is thought of as the gold standard for detection of Cryptococcus, $\mathrm{CrAg}$ had been used (latex agglutination or enzyme immunoassay) for some time as a rapid surrogate [43]. CrAg LFA is a 'dipstick' test, costing $\$ 2$ per test in 


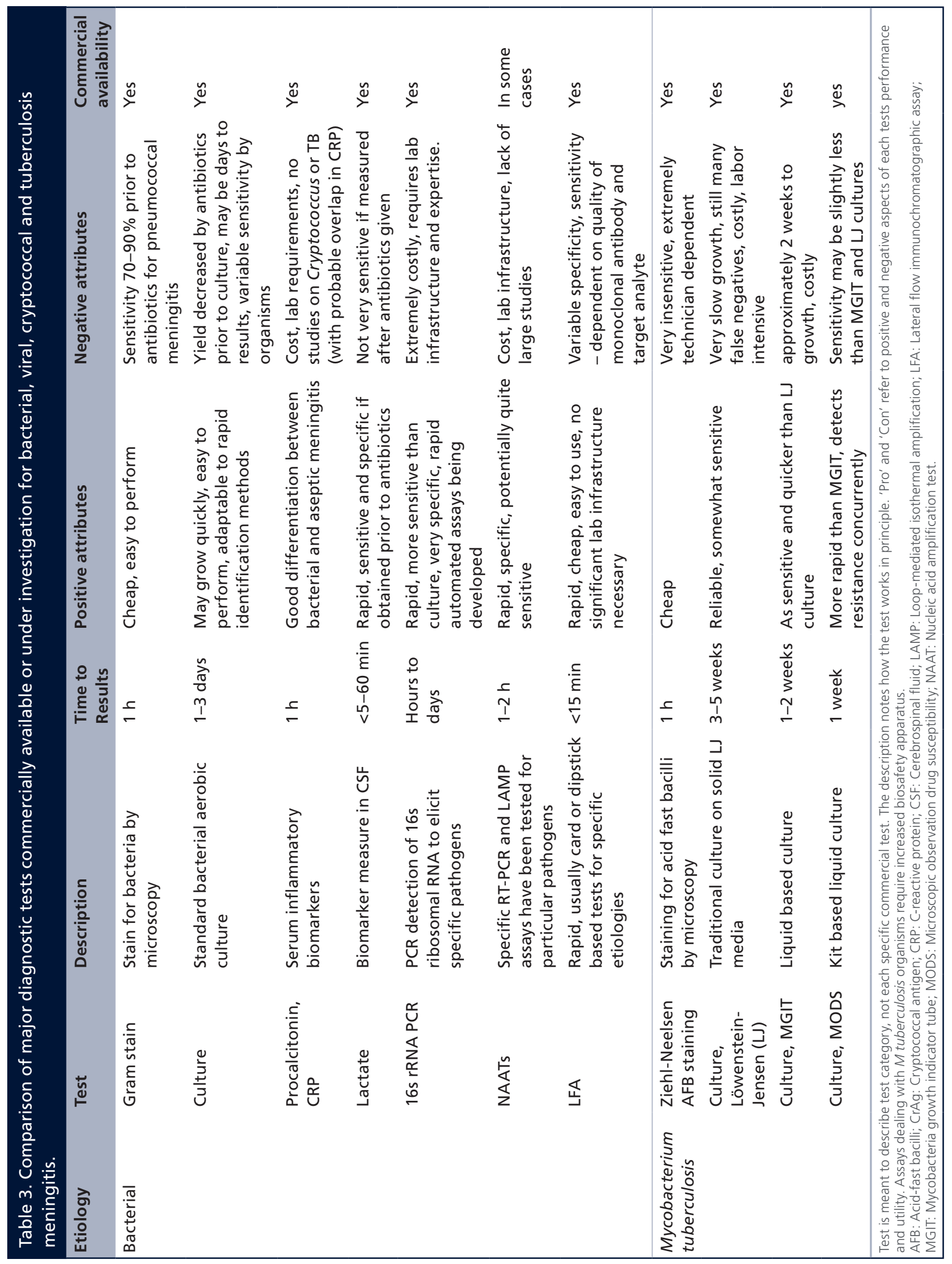




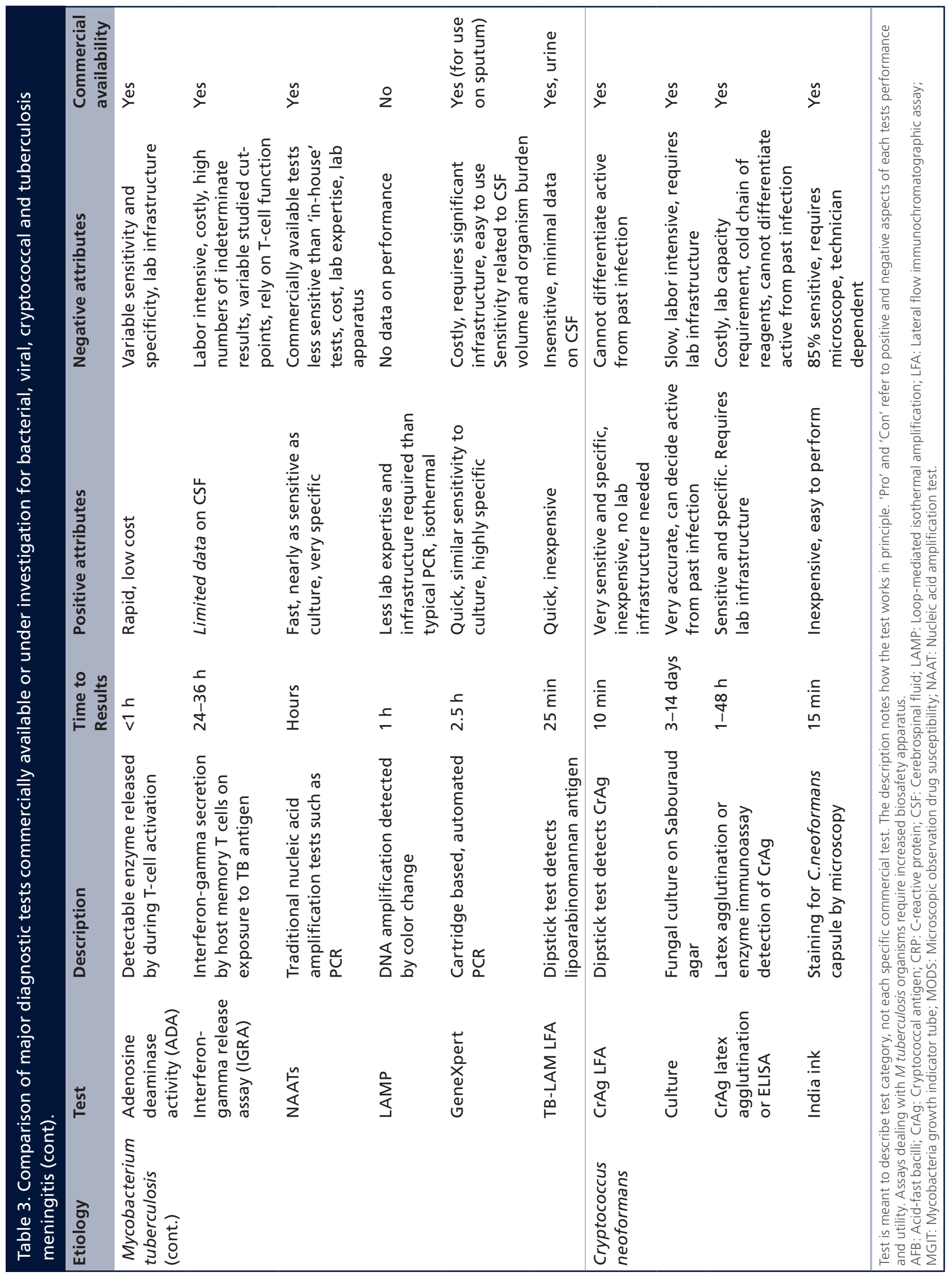




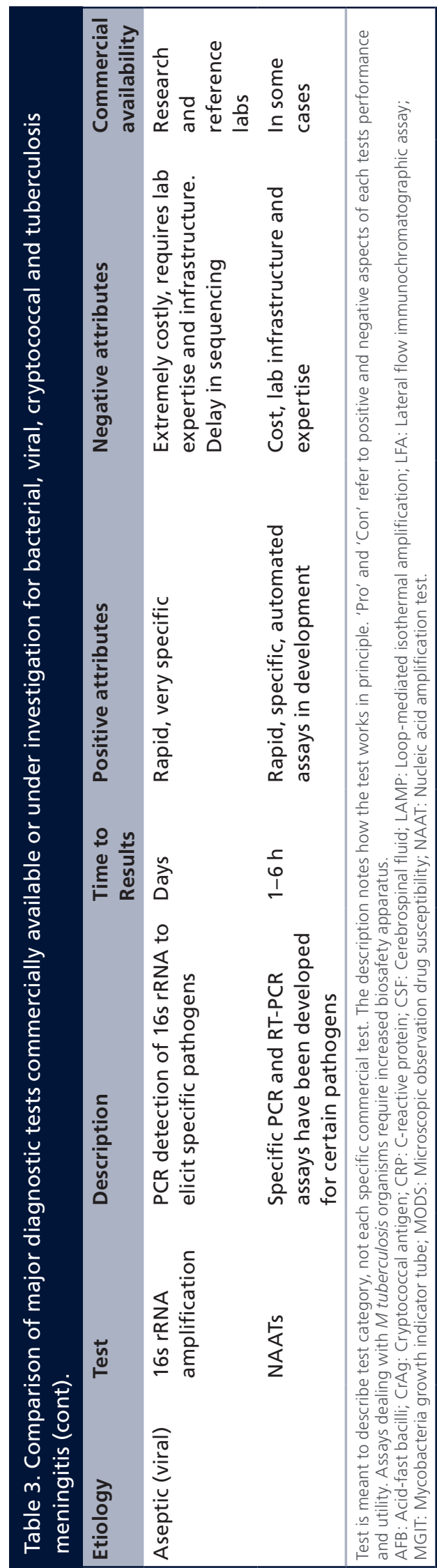

low-income countries (US\$5 in high income), and is ideal for the environments (warm climate, low-middle income countries) where much of the world's cryptococcosis occurs [43]. The LFA requires only a drop of blood or CSF, is quick (10 min), and is easy to interpret. More importantly, the CrAg LFA can be shipped and stored at room temperature, and does not require lab infrastructure or cold chain transport that the traditional $\mathrm{CrAg}$ latex agglutination did [43]. In a multisite study in Africa of 666 persons with suspected meningitis, the sensitivity of the LFA was $99.3 \%$, specificity $99.1 \%$, positive predictive value $99.5 \%$ and negative predictive value $98.7 \%$ [78]. Importantly, CSF LFA CrAg was actually more sensitive than culture in this study, whereby a composite reference standard defined cryptococcal infection [78]. Titers can be performed with the LFA, which are a median 2.5-fold higher titers than CrAg latex agglutination, and titer level corresponds with mortality [78,79]

The LFA has now been validated in CSF, urine, serum, plasma, whole blood and by finger stick, and has European CE marking for these specimen types [78,80-82]. One important limitation of any $\mathrm{CrAg}$ assay (LFA included) is that the antigen persists long after culture sterility in the range of months to years [83,84]. Thus, in a patient with a history of cryptococcosis, CSF CrAg may indicate culture-positive relapse, cryptococcal-IRIS or a prior resolved infection, distracting from another, true cause of meningitis.

In addition to LFA, the India ink microscopy, $\mathrm{CrAg}$ latex agglutination and ELISA CrAg assays also exist. In high-quality lab settings, India ink microscopy has sensitivity of approximately $85 \%$ [78]. India ink is particularly problematic for early and/or low burden infections, whereby sensitivity is only $40 \%$ with CSF cultures having $<1000$ Cryptococcus $\mathrm{CFU} / \mathrm{ml}$ [78]. Culture is a mainstay, yet not rapid. Cryptococcal-IRIS is a particularly difficult diagnosis. History (timing of ART) is crucial but as noted above, CrAg can be difficult to interpret in this setting and so one relies on culture. A paucity of initial CSF inflammation (i.e., normal CSF WBC count and protein) is predictive of higher probability of future cryptococcal-IRIS [73,85].

Diagnosis of meningitis due to endemic fungal infection (e.g., histoplasmosis, blastomycosis, coccidiomycosis) has traditionally relied on culture or identification from another body site in the presence of CNS inflammation - neither of these options has adequate sensitivity. Histoplasma and Blastomyces antigen (Mira Vista Diagnostics, IN, USA) can be detected in CSF (relatively unknown sensitivity: 35\% (5/14) for Histoplasma and 3 of 3 in a case series of CNS Blastomyces) as can Histoplasma antibodies (approximately 75\% sensitivity) [37,38,86]. The 1,3-beta-D-glucan (Fungitell ${ }^{\circledR}$, 
Cape Code Associates, MA, USA) testing of CSF performed well in the 2012 US. Exserohilum outbreak [87], and likely is possible for other mycoses including Aspergillus [88]. Diagnostic performance of beta-D-glucan on CSF is limited; however, specificity in CSF appears very high [Boulware DR, Unpublished data], thus a positive 1,3-beta-D-glucan result most probably reflects CNS fungal disease.

\section{Diagnostic tests for TBM}

Diagnosis of TBM is extremely difficult and so case definitions and clinical prediction rules based are often employed in clinical studies to help understand the probability of TBM [89,90]. Ziehl-Neelsen staining for acid-fast bacilli (AFB) is of limited utility, though fast, sensitivity is poor (often 10-20\%) and even with meticulous examination of large CSF volumes (which are not plausible in most settings) may be only as high as $60 \%[8,26,91]$. A recent study describing 37 cultureproven TBM patients showed a sensitivity of just 3.3\% (95\% CI: 1.6-6.7\%) with traditional AFB staining but with an altered protocol involving cytospin slides and triton processing a sensitivity of $83 \%$ ( $95 \% \mathrm{CI}$ : 77-87\%) while an early secretory antigen target (ESAT)-6 immunostain allowed for 75\% (95\% CI: 69-81\%) sensitivity [92]. Traditional Lowenstein-Jensen (LJ) solid media culture is generally $60-70 \%$ sensitive, but its clinical utility is limited by the $4-5$-week average time to a positive result $[91,93]$, whereas mycobacterial growth indicator tube (MGIT) culture often takes approximately 2 weeks [94]. Culture is too slow to direct treatment of TBM. Another culture technique, microscopic observation drug susceptibility (MODS) was found to be $65 \%$ sensitive while MGIT and LJ cultures both were $70 \%$ sensitive in a study where $42 \%$ of CSF specimens in persons suspected to have TBM grew M. tuberculosis [94]. In this study, the major advantage of MODS was median time to diagnosis of 6 days for MODS (IQR: 5-7days) versus 15.5 days (IQR: 12-24 days) for MGIT and 24 days (IQR: 8-25 days) for LJ solid media cultures [94]. Although 6 days is an improvement, this is still a significant delay - often deterioration of the patient's condition necessitates empiric treatment long before 6 days. Exclusion of all other treatable conditions and empiric TB therapy remain the norm; however, some novel $\mathrm{TB}$ assays appear promising which may change the paradigm.

Adenosine deminase (ADA) was evaluated in a small Spanish retrospective study of 16 TBM patients with $62.5 \%$ sensitivity among culture-proven TBM, using ADA threshold of $>10$ IU/l [26]. A 2010 systematic review of 10 TBM studies reported a mean ADA sensitivity of $79 \%$ (95\% CI: $75-83 \%)$ with a mean specificity of $91 \%$ (95\% CI: 89-93\%), with two substantial caveats [95]. Across studies, there was substantial variation in the ADA threshold considered abnormal (range of 5-15.5 IU/l) and substantial variation in the range of sensitivity reported (50-100\%) [95]. The concept of ADA has been present for some time, but has not gained widespread use in TBM.

Interferon gamma release assays (IGRAs) have been evaluated on CSF for the diagnosis of TBM in multiple studies. One Korean study of HIV-negative patients ( 25 with definite or probable TBM and 57 classified as not having TBM by clinical characteristics) showed a sensitivity of $72 \%(95 \%$ CI: $51-88 \%)$ and specificity of $79 \%$ (95\% CI: 66-89\%) [96], the same group published a study 2 years prior with 59\% sensitivity (95\% CI: 36-79\%) and specificity of 89\% (95\% CI: 72-98\%) [97]. A South African study of 86 patients ( $87 \%$ HIV positive), 38 with TBM by culture or PCR (median CD4: 84; IQR: 53-173) and 48 classified as non-TBM (median CD4: 161; IQR: 54-261) showed sensitivity of $84 \%$ (95\% CI: 69-94\%) and specificity of $73 \%(58-85 \%)$ [98]. This is an important study as IGRAs rely to some degree on T-cell function, yet despite advanced HIV infection, the IGRA was relatively sensitive. All studies had high numbers of inconclusive results and different cut-points with the same assay (T-spot: 6 vs 20 positive spots) [96-97]. IGRA are currently relatively expensive, requires overnight processing and specialized equipment [98] limiting the utility of IGRA for TBM at present.

A lipoarabinomannan (LAM) antigen detection test (Clearview $^{\circledR}$ TB ELISA, ME, USA) was evaluated on CSF in 150 patients ( $84 \%$ were infected with HIV) 39 were classified as definite TBM and 54 as not having TBM [90]. Sensitivity was 31\% (95\% CI: 17-48\%) and specificity $94 \%$ (95\% CI: 85-94\%), performance improved with decreased CD4 count [90]. A Brazilian study of 83 patients (19 with TBM, 62 without TBM) evaluated the Lionex TB ELISA kit along with numerous $M$ tuberculosis antigens (MPT-64 [Rv1980c], MT10.3 [Rv3019c], $16 \mathrm{kDa}$ [2031c] and $38 \mathrm{kDa}$ [Rv0934]) (Lionex Diagnostics and Therapeutics, Germany) in various combinations on CSF [99]. Sensitivity ranged from 10.5 to $63.2 \%$ with specificities from 78.1 to $96.7 \%$ [99].

Nucleic acid amplification tests (NAATs), both RNA and DNA, are very specific. A 2003 meta-analysis of 14 commercial and 35 'in-house' nucleic acid amplification tests found mean sensitivity was $71 \%$ (95\% CI: $63-77 \%)$ with mean specificity of $95 \%$ (95\% CI: 92-97\%) [100]. Interestingly commercial tests (primarily RNA based) showed mean sensitivity of 56\% (95\% CI: 46-66\%) while 'in-house' tests (primarily DNA based) had a mean sensitivity of $76 \%$ (95\% CI: 67-83\%), mean specificities were $98 \%$ 
(95\% CI: 97-99\%) and 92\% (95\% CI: 88-95\%), respectively [100]. A 2014 meta-analysis of NAATs included studies from 2003-2013; pooled estimates of 9 commercial tests showed sensitivity and specificity were 64\% (95\% CI: 56-72\%) and 98\% (95\% CI: 96-99\%), respectively [101]. Though it appears that sensitivity has improved in commercially available tests since the 2003 meta-analysis above, among 40 commercially available tests sensitivity and specificity were very more or less unchanged [101]. Unfortunately cost and the significant lab infrastructure and expertise required to run these tests (even the less onerous commercial tests) limits their utility to some degree.

Loop-mediated isothermal amplification (LAMP) is a DNA amplification technology that requires much less infrastructure than traditional PCR and so is very attractive for use in low-middle income countries where much of the world's TBM occurs. One small Indian study of 27 patients (17 with TBM, 10 without TBM) found $88 \%$ sensitivity (95\% CI: 64-98.5\%) and $80 \%$ specificity ( $95 \%$ CI: 44-98\%) based on clinical diagnosis [102]. LAMP requires further evaluation.

The MTB/Rif cartridge used with the GeneXpert system (Cepheid, CA, USA) has been a significant breakthrough in TB diagnostics [8]. This system is expensive ( $\$ 16,000$ in low/middle income countries), but its cartridge-based platform ( $\$ 10 /$ cartridge discounted cost, $\$ 60$ regular cost) decreases the need for lab expertise. The only requirement is reliable electricity. GeneXpert has been extensively studied on sputum but less so on CSF. Three studies of extrapulmonary TB suspects in Italy and Spain reported variable sensitivity but high specificity in GeneXpert use in a small number of cases [103-105]. All three studies looked at multiple extrapulmonary sites in aggregate, and CSF contributed a relatively small amount of samples, thus it is difficult to draw firm conclusions from these studies. However, GeneXpert appeared promising. More recently, in a South African study of 54 patients with TBM (by microbiology) and 65 non-TBM patients found sensitivity of the Xpert MTB/Rif cartridge was $67 \%$ (95\% CI: $53-79 \%)$ while specificity was 94\% (95\% CI: 85-98\%), sensitivity was significantly improved with centrifuged samples (Xpert positive in $22 / 27$ ) versus uncentrifuged samples (Xpert positive in 20/39) [63]. A Vietnamese study of 379 patients (182 with definite or probable TBM and 197 who did not have TBM) showed 59\% (95\% CI: 52-67\%) sensitivity for patients with definite or probable TBM by clinical criteria with $99 \%$ specificity (1 false positive of 197 negative samples) [64]. As a reference, sensitivity for MGIT culture was 66\% (95\% CI: $59-73 \%)$ and 79\% (95\% CI: 72-84\%) with AFB staining described as meticulous with large volumes [64]. A 2014 meta- analysis showed pooled sensitivity of $70 \%$ and specificity of $97 \%$ [101]. More data are required; however, GeneXpert appears to be helpful due to its ease of use, rapidity of the test and high specificity. Negatives of the GeneXpert include cost of the assay and the imperfect sensitivity. The key aspect to GeneXpert sensitivity is that GeneXpert detection threshold is approximately 80-100 M. tuberculosis organisms per test cartridge [106]. Regardless of the specimen type, one needs sufficient DNA present. Unfortunately, TBM has a paucity of organisms, thus there is imperfect sensitivity with nonconcentrated CSF.

\section{Diagnostic tests for bacterial meningitis}

Gram stain and CSF culture are the most common tests (specific to bacterial meningitis) used to diagnose bacterial meningitis. Culture is the gold standard, aerobic culture is generally sufficient although in special cases (such as those patients with recent neurosurgery) anaerobic culture is warranted [5]. Culture is generally a good diagnostic test with sensitivities of $60-90 \%$ commonly quoted, if collected prior to antibiotics [5,107]. Gram stain is less reliable but is quick and inexpensive. Sensitivities are frequently between 40 and $70 \%$ and may yield a helpful result in $30-50 \%$ of culture negative patients [5,107], particularly in the setting of antibiotic treatment prior to culture (although Gram stain yield decreases to some degree in this setting as well) [5]. Blood culture may also be used and yields results in $50-90 \%$ of patients with bacterial meningitis (varying by organism) [5]. Latex agglutination tests for bacterial antigens have used for many years for a variety of common organisms, including: S. pneumoniae, N. meningitidis, Group B Streptococcus, H. influenza type B and Escherichia coli. Their increase in sensitivity over Gram's stain and culture is relatively modest, and these require similar cold chain and lab infrastructure as the CrAg latex agglutination, thus are not used widely in low- and middle-income countries. Lateral flow immunochromatographic assays have also been developed for meningococcal and pneumococcal meningitis with excellent sensitivity and specificity [108,109], although LFA performance is more variable for $N$. meningitidis [110].

Procalcitonin and C-reactive protein (CRP) are serum biomarkers that may have some roll in differentiating bacterial meningitis from other meningitidis. A 1999 study of 23 patients with bacterial meningitis and 57 patients with viral meningitis showed substantial differences in procalcitonin between bacterial meningitis (mean: $13.8 \mathrm{ng} / \mathrm{ml}$; range: $0.22-101 \mathrm{ng} /$ $\mathrm{ml}$ ) and viral meningitis (mean: $0.03 \mathrm{ng} / \mathrm{ml}$; maximum: $0.1 \mathrm{ng} / \mathrm{ml}$ ) [107]. Another 2007 study of patients with acute meningitis showed significant differences in CRP and procalcitonin values between bacterial 
meningitis $(\mathrm{n}=18)$ and aseptic meningitis $(\mathrm{n}=133)$. Patients with bacterial meningitis had a median CRP value of $162 \mathrm{mg} / \mathrm{l}$ (IQR: 39-275 mg/l) and a median procalcitonin level of $3.75 \mathrm{ng} / \mathrm{ml}$ (IQR: 0.1-6.16 ng/ $\mathrm{ml}$ ) compared with patients with aseptic meningitis with median CRP levels of $13 \mathrm{mg} / \mathrm{l}$ (IQR: 9-17 mg/l) and procalcitonin of $0.07 \mathrm{ng} / \mathrm{ml}$ (IQR: $0-0.8 \mathrm{ng} /$ $\mathrm{ml}$ ), respectively [67]. A 2011 meta-analysis (33 studies) of CSF lactate (cut-off $35 \mathrm{mg} / \mathrm{dl}$ ) showed sensitivity of $93 \%$ (95\% CI: 89-96\%) and specificity of 96\% (95\% CI: 93-98\%) [111]. Sensitivity dropped to $49 \%$ (95\% CI: $23-75 \%$ ) if antibiotics were given prior to lumbar puncture [111]. These three tests (procalcitonin, CRP, CSF lactate) are generally used as adjunct tests when they are used. However, the relatively low cost of a serum CRP may be useful to guide whether more extensive testing is sought and the response to therapy.

In culture-negative, pyogenic meningitis with elevated inflammatory serum biomarkers (e.g., procalcitonin, CRP), 16s ribosomal RNA (rRNA) PCR is an exciting new technology that allows for definitive identification of bacteria. A 2012 meta-analysis of 14 studies of 16s rRNA PCR (448/2780 CSF samples were culture positive) for use in bacterial meningitis showed 92\% (95\% CI: 75-98\%) sensitivity and 94\% (95\% CI: 90-97\%) specificity compared with culture [112]. Further, 16s rRNA PCR identified pathogens in $33 \%$ of 360 cases of presumed culture negative bacterial meningitis though definitions of presumed bacterial meningitis varied broadly and sensitivities of individual studies varied widely (3-100\%) [112]. The major role of 16s PCR is for culture negative meningitis, particularly when antecedent antibiotics have been received and/ or with elevated biomarkers. CSF collection and processing must be strictly sterile, as any contamination of CSF at any point can introduce environmental flora.

Lastly, a number of assays have been tested for specific bacterial etiologies though their use is not widespread. LAMP use in separate studies detecting $H$. influenza and $S$. pneumoniae actually outperformed conventional PCR and specificity was $100 \%[113,114]$. RT-PCR developed to combat the changing serotype epidemiology of $H$ influenza showed proof of concept in detecting all known samples of $H$ influenza nonserotype B [115] and has been used to detect $L$. monocytogenes [16].

\section{Diagnostic tests for aseptic meningitis}

A number of very specific (conventional PCR, 16s rRNA, RT-PCR) tests have been developed for detection of the etiologies responsible for aseptic meningitis $[117,118]$. We will not, however, devote significant space to these tests as with some exceptions, the specific etiology is not treatable and so the clinical utility is minimal for many of these tests [119]. Further, as noted above, the important distinction is bacterial versus aseptic meningitis. Gram stain, culture, glucose and cell count, and to a lesser degree procalcitonin, CRP, or lactate provide compelling evidence to assist the clinician. Newer rapid multiplex assays are in development, but there is as yet published data.

\section{Barriers to adoption}

Cost remains a significant barrier for many new molecular diagnostics both in high-income and low/ middle-income countries. Excluding reference laboratories, most local hospital microbiology labs are costs to a healthcare system, not a revenue generator. An integrated health system approach needs to be considered for decision making. A new relatively expensive assay may cost more for a microbiology laboratory budget, yet accrue significant cost savings in avoidance of other unnecessary procedures/testing, decreased pharmaceutical costs for empiric treatments and shorter duration of hospitalization. A second, ironic barrier to adoption is the standard Good Clinical Lab Practice of every laboratory internally validating a new assay. For fully automated US FDA-approved molecular assays, this slows adoption for relatively rare diseases where validation takes significant time and effort. Third, as new molecular tests become available, how best to utilize such testing in a cost-effective manner in highand low-income settings needs to be explored [47]. Lastly, the patchwork of individual country regulatory requirements, which are often unclear or unknown in low- and middle-income countries, creates a substantial disincentive for manufacturers to bring new FDA-approved and/or CE-marked diagnostic assays to markets where there is minimal financial return. These barriers unfortunately impact vulnerable patients with deadly diseases, foremost.

\section{Conclusion}

Diagnosing the specific etiology of meningitis is crucial in bacterial, TB and cryptococcal meningitis - delays in diagnosis increase mortality. In order to rationally select which additional diagnostic tests might prove useful in making the proper diagnosis, physicians should pay close attention to time course of symptoms, past medical history, travel history, country of origin, sexual history, history of drug use, regional epidemiology and the patient's immune status. Thankfully, for bacterial meningitis and cryptococcal meningitis, excellent diagnostic tests exist which can help make a rapid diagnoses. Progress is being made with TBM diagnostics but delay in diagnosis still costs many lives. Further dissemination of technologies such as GeneXpert and 16s ribosomal PCR will certainly lead to improved care. Worldwide, point-of-care lateral flow assays, such as the 
CrAg LFA, an ideal test for meningitis diagnostics that stakeholders should strive to emulate.

\section{Future perspective}

The field of diagnostics for infectious diseases is currently undergoing a renaissance in the development of new molecular assays with increased automation. GeneXpert is the first such broadly rolled out platform technology, and others such as the Biofire Diagnostics FilmArray platform are in development. In the next 5 years, these automated nucleic acid amplification tests will likely become more common place in high-income countries. Lateral flow assays will likely become more commonplace in all of infectious disease diagnostics, including meningitis. An unresolved question is the degree to which new diagnostics will become available in low-income countries. Significant regulatory and market barriers exist for actual implementation in resource-limited settings.

Financial \& competing interests disclosure

The authors are supported by the National Institute of Neurologic Diseases and Stroke (NINDS), National Institute of Allergy and Infectious Diseases (NIAID), and Fogarty International Center (R01NS086312, R25TW009345, U01A1089244, T32Al055433). The authors have no other relevant affiliations or financial involvement with any organization or entity with a financial interest in or financial conflict with the subject matter or materials discussed in the manuscript apart from those disclosed.

No writing assistance was utilized in the production of this manuscript.

\section{Executive summary}

\section{Background}

- Meningitis may be due to bacteria, mycobacteria (e.g., Mycobacterium tuberculosis), fungi (predominantly Cryptococcus neoformans), viruses, parasites or noninfectious causes such as malignancy or rheumatologic conditions.

- Mortality is high except in aseptic meningitis.

- Prompt diagnosis is key to successful treatment.

Epidemiology

- Streptococcus pneumoniae is the most common cause of bacterial meningitis worldwide though rates of this meningitis due to this and other bacterial pathogens shift in relation to vaccinations.

- Rates of bacterial meningitis, fungal meningitis, tuberculosis meningitis and aseptic meningitis vary widely by geographic location.

- Rates of tuberculosis and cryptococcal meningitis tend to be much higher in areas with high burdens of HIV and low-income levels.

The host

- In patients with severe immune compromise; cryptococcal meningitis is by far the most common cause of meningitis.

- Tuberculosis and bacterial meningitis are also more common in patients with abnormal immune systems than in those with normal immune function.

- Cryptococcal meningitis becomes less likely as the CD4+ T-cell count rises above $>100$ cells/ $\mu$ l.

- In addition to HIV a number of additional causes of immune compromise such as solid organ or stem cell transplant, diabetes mellitus, alcoholism, cirrhosis of the liver, use of biologic immune-suppressive medications, asplenia, cancer and chemotherapy should be considered as influences of the relative likelihood of meningitis etiologies.

Duration of symptoms

- Tuberculosis and cryptococcal meningitis tend to present as subacute meningitis.

- Bacterial meningitis is generally rapidly progressive. If the patient has had symptoms for $>1$ week they are very unlikely to have bacterial meningitis.

- Symptoms related to aseptic meningitis vary widely.

Common diagnostic laboratory \& imaging tests

- Most often patients with tuberculosis or bacterial meningitis have high cerebrospinal fluid (CSF) white blood cell and protein values with low glucose values.

- Patients with tuberculosis meningitis are less likely to have neutrophilic CSF than are those patients with bacterial meningitis.

- Patients with aseptic meningitis or cryptococcal meningitis are less likely to have inflammatory CSF.

- Imagining is generally not helpful unless persistent or focal neurologic symptoms are present.

Diagnostic tests for fungal meningitis

- Cryptococcal antigen detection by lateral flow assay is the mainstay of diagnosis in patients without previous history of cryptococcal meningitis as a fast, cheap and accurate test.

- Culture is extremely important in patients with previous history of cryptococcal meningitis. 


\section{Executive summary (cont.)}

\section{Diagnostic tests for tuberculous meningitis}

- Traditional staining for acid fast bacilli with microscopy is rapid but insensitive.

- Culture has improved sensitivity (though still poor) but growth takes weeks.

- Nucleic acid amplification tests offer some promise with sensitivity similar to culture with much improved speed.

Diagnostic tests for bacterial meningitis

- Gram staining and culture are the mainstays of diagnosis. Gram stain is more rapid while culture is more sensitive.

- Both Gram staining and culture have better sensitivity if CSF is collected prior to administration of antibiotics.

- Nucleic acid amplification tests may offer some promise in rapid, sensitive detection of bacterial meningitis.

- Rapid tests have been developed for detection of specific pathogens with variable efficacy reported.

Diagnostic tests for aseptic meningitis

- Numerous nucleic acid amplification tests are available but cost and lack of actionable treatments in many cases (combined with generally good outcomes) makes the values of these tests less clear than that of tests for other forms of infectious meningitis.

\section{Barriers to adoption}

- Major barriers to adoption of specific diagnostic tests most often include cost, required laboratory infrastructure and/or disparate regulations between countries that prevent rapid adoption.

\section{Conclusion}

- Early diagnosis of the etiologic agent of meningitis leads to improved outcomes.

- Patient history, epidemiology, patient symptoms and diagnostic tests need to be used in combination with each other to provide rapid and accurate diagnosis.

- Progress has been made in diagnostic tests for cryptococcal and bacterial meningitis while improved detection of tuberculosis meningitis remains a major priority.

\section{Future perspective}

- Increased automation in assays and use of lateral flow assays will improve the applicability of diagnostic tests to disparate settings.

- Barriers such as cost and variable regulations across countries slow widespread use of diagnostic advances.

\section{References}

Papers of special note have been highlighted as: $\bullet$ of interest; -• of considerable interest.

1 Bhimraj A. Acute community-acquired bacterial meningitis in adults: an evidence-based review. Cleve. Clin. J. Med. 79(6), 393-400 (2012).

2 Brouwer MC, Thwaites GE, Tunkel AR, van de Beek D. Dilemmas in the diagnosis of acute communityacquired bacterial meningitis. Lancet 380 (9854), 1684-1692 (2012).

3 Ersoy Y, Yetkin F, Bayraktar MR, Ersoy Y, Yologlu S. A new diagnostic scoring for discrimination of tuberculous and bacterial meningitis on the basis of clinical and laboratory findings. Med. Princ. Pract. 21(3), 259-263 (2012).

4 Thigpen MC, Whitney CG, Messonnier NE et al. Bacterial meningitis in the United States, 1998-2007. N. Engl. J. Med. 364(21), 2016-2025 (2011).

5 Brouwer MC, Tunkel AR, van de Beek D. Epidemiology, diagnosis, and antimicrobial treatment of acute bacterial meningitis. Clin. Microbiol. Rev. 23(3), 467-492 (2010).

6 Tuppeny M. Viral meningitis and encephalitis. Crit. Care Nurs. Clin. North Am. 25 (3), 363-380 (2013).

7 James SH, Kimberlin DW, Whitley RJ. Antiviral therapy for herpesvirus central nervous system infections: neonatal herpes simplex virus infection, herpes simplex encephalitis, and congenital cytomegalovirus infection. Antiviral Res. 83(3), 207-213 (2009).
8 Thwaites GE, van Toorn R, Schoeman J. Tuberculous meningitis: more questions, still too few answers. Lancet Neurol. 12(10), 999-1010 (2013).

9 Rajasingham R, Rolfes MA, Birkenkamp KE, Meya DB, Boulware DR. Cryptococcal meningitis treatment strategies in resource-limited settings: a cost-effectiveness analysis. PLoS Med. 9(9), e1001316 (2012).

10 Marais S, Pepper DJ, Schutz C, Wilkinson RJ, Meintjes G. Presentation and outcome of tuberculous meningitis in a high HIV prevalence setting. PLoS ONE 6(5), e20077 (2011).

11 Cohn AC, MacNeil JR, Harrison LH et al. Changes in Neisseria meningitidis disease epidemiology in the United States, 1998-2007: implications for prevention of meningococcal disease. Clin. Infect. Dis. 50(2), 184-191 (2010).

12 Hsu HE, Shutt KA, Moore MR et al. Effect of pneumococcal conjugate vaccine on pneumococcal meningitis. N. Engl. J. Med. 360 (3), 244-256 (2009).

13 Miller E, Andrews NJ, Waight PA, Slack MP, George RC. Herd immunity and serotype replacement 4 years after seven-valent pneumococcal conjugate vaccination in England and Wales: an observational cohort study. Lancet Infect. Dis. 11(10), 760-768 (2011).

14 National Institute for Communicable Diseases. Group for enteric, respiratory and meningeal disease surveillance in South Africa. In: GERMS-SA Annual Report 2012. Meiring, S, Quan, V, Govender, N, Crowther-Gibson, P (Eds). Johannesburg, South Africa (2012). 
15 Gessner BD, Mueller JE, Yaro S. African meningitis belt pneumococcal disease epidemiology indicates a need for an effective serotype 1 containing vaccine, including for older children and adults. BMC Infect. Dis. 10, 22 (2010).

16 McIntyre PB, O’Brien KL, Greenwood B, van de Beek D. Effect of vaccines on bacterial meningitis worldwide. Lancet 380 (9854), 1703-1711 (2012).

17 Coulson GB, von Gottberg A, du Plessis M et al. Meningococcal disease in South Africa, 1999-2002. Emerg. Infect. Dis. 13(2), 273-281 (2007).

18 Mohammed I, Nasidi A, Alkali AS et al. A severe epidemic of meningococcal meningitis in Nigeria, 1996. Trans. R. Soc. Trop. Med. Hyg. 94(3), 265-270 (2000).

19 Daugla DM, Gami JP, Gamougam K et al. Effect of a serogroup A meningococcal conjugate vaccine (PsA-TT) on serogroup A meningococcal meningitis and carriage in Chad: a community study. Lancet 383(9911), 40-47 (2014).

- Demonstrates the elimination of meningococcal meningitis serotype A and carriage with community-wide vaccination. Ongoing implementation of vaccination will likely greatly decrease the burden of meningococcal disease in the meningitis belt of Africa.

20 Zipursky S, Djingarey MH, Lodjo J-C, Olodo L, Tiendrebeogo $\mathrm{S}$, Ronveaux $\mathrm{O}$. Benefits of using vaccines out of the cold chain: delivering meningitis $A$ vaccine in a controlled temperature chain during the mass immunization campaign in Benin. Vaccine 32(13), 1431-1435 (2014).

21 Ladhani S, Slack MP, Heys M, White J, Ramsay ME. Fall in Haemophilus influenzae serotype b (Hib) disease following implementation of a booster campaign. Arch. Dis. Child. 93(8), 665-669 (2008).

22 Schrag SJ, Zywicki S, Farley MM et al. Group B streptococcal disease in the era of intrapartum antibiotic prophylaxis. N. Engl. J. Med. 342(1), 15-20 (2000).

23 Phares CR, Lynfield R, Farley MM et al. Epidemiology of invasive group B streptococcal disease in the United States, 1999-2005. JAMA 299 (17), 2056-2065 (2008).

24 World Health Organisation. Global Tuberculosis Report 2012. 1-6 (2012).

25 Riddell JT, Shuman EK. Epidemiol. Centr. Nerv. Syst. Infect. Neuroimag. Clin. N. Am. 22(4), 543-556 (2012).

26 Berenguer J, Moreno S, Laguna F et al. Tuberculous meningitis in patients infected with the human immunodeficiency virus. N. Engl. J. Med 326(10), 668-672 (1992).

27 Jarvis JN, Meintjes G, Williams A, Brown Y, Crede T, Harrison TS. Adult meningitis in a setting of high HIV and TB prevalence: findings from 4961 suspected cases. $B M C$ Infect. Dis. 10, 67 (2010).

- Reports the etiologies of adult meningitis in Cape Town, South Africa reflecting the impact of HIV has had on the etiologies of meningitis.

28 Woldeamanuel YW, Girma B. A 43-year systematic review and meta-analysis: case-fatality and risk of death among adults with tuberculous meningitis in Africa. J. Neurol. 261(5) , 851-865 (2013).
29 CDC. Emergence of Cryptococcus gattii - Pacific Northwest, 2004-2010. Morbid. Mortal. Wkly. Rep. 59(28), 865-868 (2010).

30 Ecevit IZ, Clancy CJ, Schmalfuss IM, Nguyen MH. The poor prognosis of central nervous system cryptococcosis among nonimmunosuppressed patients: a call for better disease recognition and evaluation of adjuncts to antifungal therapy. Clin. Infect. Dis. 42(10), 1443-1447 (2006).

31 Loyse A, Wilson D, Meintjes G et al. Comparison of the early fungicidal activity of high-dose fluconazole, voriconazole, and flucytosine as second-line drugs given in combination with amphotericin B for the treatment of HIVassociated cryptococcal meningitis. Clin. Infect. Dis. 54(1), 121-128 (2012).

32 Park BJ, Wannemuehler KA, Marston BJ, Govender N, Pappas PG, Chiller TM. Estimation of the current global burden of cryptococcal meningitis among persons living with HIV/AIDS. AIDS 23(4), 525-530 (2009).

33 Cohen DB, Zijlstra EE, Mukaka M et al. Diagnosis of cryptococcal and tuberculous meningitis in a resourcelimited African setting. Trop. Med. Int. Health 15(8), 910-917 (2010).

34 National Institute for Communicable Diseases. Group for Enteric, Respiratory and Meningeal Disease Surveillance in South Africa (GERMS-SA). In: GERMS-SA Annual Report 2011. Govender N, Quan V (Eds). Johannesburg, South Africa (2011).

35 Smith RM, Schaefer MK, Kainer MA et al. Fungal infections associated with contaminated methylprednisolone injections. N. Engl. J. Med. 369 (17), 1598-1609 (2013).

36 Johnson RH, Einstein HE. Coccidioidal meningitis. Clin. Infect. Dis. 42(1), 103-107 (2006).

37 Bariola JR, Perry P, Pappas PG et al. Blastomycosis of the central nervous system: a multicenter review of diagnosis and treatment in the modern era. Clin. Infect. Dis. 50(6), 797-804 (2010).

38 Wheat LJ, Batteiger BE, Sathapatayavongs B. Histoplasma capsulatum infections of the central nervous system. Clin. Rev. Med. 69(4), 244-260 (1990).

39 Rotbart HA, Brennan PJ, Fife KH et al. Enterovirus meningitis in adults. Clin. Infect. Dis. 27(4), 896-898 (1998).

40 Kupila L, Vuorinen T, Vainionpaa R, Hukkanen V, Marttila RJ, Kotilainen P. Etiology of aseptic meningitis and encephalitis in an adult population. Neurology 66(1), 75-80 (2006).

41 Lee BE, Davies HD. Aseptic meningitis. Curr. Opin. Infect. Dis. 20(3), 272-277 (2007).

42 Soares CN, Cabral-Castro MJ, Peralta JM, de Freitas MR, Zalis M, Puccioni-Sohler M. Review of the etiologies of viral meningitis and encephalitis in a dengue endemic region. J. Neurol. Sci. 303(1-2), 75-79 (2011).

43 Rajasingham R, Meya DB, Boulware DR. Integrating cryptococcal antigen screening and pre-emptive treatment into routine HIV care. J. Acquire. Immune Defic. Syndr. 59(5), e85-e91 (2012). 
44 Thwaites GE. Advances in the diagnosis and treatment of tuberculous meningitis. Curr. Opin. Neurol. 26(3), 295-300 (2013).

Bekondi C, Bernede C, Passone N et al. Primary and opportunistic pathogens associated with meningitis in adults in Bangui, Central African Republic, in relation to human immunodeficiency virus serostatus. Int. J. Infect. Dis. 10(5), 387-395 (2006).

Domingo P, Suarez-Lozano I, Torres F et al. Bacterial meningitis in HIV-1-infected patients in the era of highly active antiretroviral therapy. J. Acq. Immune Defic. Syndr. 51(5), 582-587 (2009).

47 Durski KN, Kuntz KM, Yasukawa K, Virnig BA, Meya DB, Boulware DR. Cost-effective diagnostic checklists for meningitis in resource-limited settings. J. Acq. Immune Defic. Syndr. 63(3), e101-e108 (2013).

- Proposes a diagnostic algorithm for meningitis in subSaharan Africa among populations with high prevalence of HIV. The use of cost-effectiveness has been minimal to date in the realm of infectious disease diagnostics, and this study demonstrates a decrease in healthcare costs while improving diagnostic accuracy with the use of stepwise and targeted testing.

48 Bahr N, Boulware DR, Marais S, Scriven J, Wilkinson RJ, Meintjes G. Central nervous system immune reconstitution inflammatory syndrome. Curr. Infect. Dis. Rep. 15(6), 583-593 (2013).

49 Meya DB, Manabe YC, Castelnuovo B et al. Costeffectiveness of serum cryptococcal antigen screening to prevent deaths among HIV-infected persons with a $\mathrm{CD} 4^{+}$ cell count $<$ or $=100$ cells $/$ microL who start HIV therapy in resource-limited settings. Clin. Infect. Dis. 51(4), 448-455 (2010).

50 Newland A, Provan D, Myint S. Preventing severe infection after splenectomy. BMJ 331(7514), 417-418 (2005).

51 Adriani KS, Brouwer MC, van der Ende A, van de Beek D. Bacterial meningitis in adults after splenectomy and hyposplenic states. Mayo Clin. Proc. 88(6), 571-578 (2013).

52 Martinot M, Oswald L, Parisi E et al. Immunoglobulin deficiency in patients with Streptococcus pneumoniae or Haemophilus influenzae invasive infections. Int. J. Infect. Dis. 19, 79-84 (2014).

53 Domingo P, Barquet N, Alvarez M, Coll P, Nava J, Garau J. Group B streptococcal meningitis in adults: report of twelve cases and review. Clin. Infect. Dis. 25(5), 1180-1187 (1997).

54 Brouwer MC, van de Beek D, Heckenberg SG, Spanjaard L, de Gans J. Community-acquired Listeria monocytogenes meningitis in adults. Clin. Infect. Dis. 43(10), 1233-1238 (2006).

55 Cabellos C, Viladrich PF, Ariza J, Maiques JM, Verdaguer $\mathrm{R}$, Gudiol F. Community-acquired bacterial meningitis in cirrhotic patients. Clin. Microbiol. Infect. 14(1), 35-40 (2008).

56 Castro Marquez C, Castro Laria L, Arguelles Arias F, Herrerias JM. Residual hydrocephalus after tuberculous meningitis in a patient with biological therapy. Inflamm. Bowel Dis. 17(6), E33-E34 (2011).
57 Girardi K, Paviglianiti A, Cirillo M et al. Tuberculous meningoencephalitis in a patient with hairy cell leukemia in complete remission. J. Clin. Exp. Hematopathol. 52(1), 31-34 (2012).

58 Petramfar P, Yousefian M, Ashraf MH, Davarpanah MA, Rahmati H. Meningoencephalitis with Aspergillus and Mycobacterium tuberculosis in a renal transplant recipient. Exp. Clin. Transplant. 9(1), 68-71 (2011).

59 Perfect JR, Dismukes WE, Dromer F et al. Clinical practice guidelines for the management of cryptococcal disease: 2010 update by the infectious diseases society of america. Clin. Infect. Dis. 50(3), 291-322 (2010).

60 Dismukes WE, Cloud G, Gallis HA et al. Treatment of cryptococcal meningitis with combination amphotericin B and flucytosine for four as compared with six weeks. N. Engl. J. Med. 317(6), 334-341 (1987).

61 Sethi NK, Torgovnick J, Sethi PK. Cryptococcal meningitis after Imuran (azathioprine) therapy for autoimmune hepatitis. Eur. J. Gastroenterol. Hepatol. 19(10), 913-914 (2007)

62 Schmidt-Hieber M, Schwender J, Heinz WJ et al. Viral encephalitis after allogeneic stem cell transplantation: a rare complication with distinct characteristics of different causative agents. Haematologica 96(1), 142-149 (2011).

63 Patel VB, Theron G, Lenders L et al. Diagnostic accuracy of quantitative PCR (Xpert MTB/RIF) for tuberculous meningitis in a high burden setting: a prospective study. PLoS Med. 10 (10), e1001536 (2013).

-• Along with [62], reports on the utility of GeneXpert MTB/RIF assay in testing CSF for the diagnosis of TB meningitis. The studies reveal imperfect sensitivity with assay sensitivity highly dependent on the volume of CSF tested.

64 Nhu NT, Heemskerk D, Thu do DA et al. Evaluation of GeneXpert MTB/RIF for diagnosis of tuberculous meningitis. J. Clin. Microbiol. 52(1), 226-233 (2014).

65 Thwaites GE, Chau TT, Stepniewska K et al. Diagnosis of adult tuberculous meningitis by use of clinical and laboratory features. Lancet 360 (9342), 1287-1292 (2002).

66 Amaya-Villar R, Garcia-Cabrera E, Sulleiro-Igual E et al. Three-year multicenter surveillance of community-acquired listeria monocytogenes meningitis in adults. BMC Infect. Dis. 10, 324 (2010).

67 Ray P, Badarou-Acossi G, Viallon A et al. Accuracy of the cerebrospinal fluid results to differentiate bacterial from non bacterial meningitis, in case of negative gram-stained smear. Am. J. Emerg. Med25(2), 179-184 (2007).

68 Kambugu A, Meya DB, Rhein J et al. Outcomes of cryptococcal meningitis in Uganda before and after the availability of highly active antiretroviral therapy. Clin. Infect. Dis. 46(11), 1694-1701 (2008).

69 Day JN, Chau TT, Lalloo DG. Combination antifungal therapy for cryptococcal meningitis. N. Engl. J. Med, 368(26), 2522-2523 (2013).

70 Mohan S, Jain KK, Arabi M, Shah GV. Imaging of meningitis and ventriculitis. Neuroimaging Clin. N. Am. 22(4), 557-583 (2012). 
71 Helbok R, Pongpakdee S, Yenjun S et al. Chronic meningitis in Thailand. Clinical characteristics, laboratory data and outcome in patients with specific reference to tuberculosis and cryptococcosis. Neuroepidemiology 26(1), 37-44 (2006).

72 Hakim JG, Gangaidzo IT, Heyderman RS et al. Impact of HIV infection on meningitis in Harare, Zimbabwe: a prospective study of 406 predominantly adult patients. Aids 14(10), 1401-1407 (2000).

73 Boulware DR, Bonham SC, Meya DB et al. Paucity of initial cerebrospinal fluid inflammation in cryptococcal meningitis is associated with subsequent immune reconstitution inflammatory syndrome. J. Infect. Dis. 202(6), 962-970 (2010).

74 Altun O, Almuhayawi M, Ullberg M, Ozenci V. Clinical evaluation of the filmarray blood culture identification panel in identification of bacteria and yeasts from positive blood culture bottles. J. Clin. Microbiol. 51(12), 4130-4136 (2013).

75 Ruggiero P, McMillen T, Tang YW, Babady NE. Evaluation of the BioFire FilmArray respiratory panel and the GenMark eSensor respiratory viral panel on lower respiratory tract specimens. J. Clin. Microbiol. 52(1), 288-290 (2014).

76 Rath PM, Schoch B, Adamzik M, Steinmann E, Buer J, Steinmann J. Value of multiplex PCR using cerebrospinal fluid for the diagnosis of ventriculostomy-related meningitis in neurosurgery patients. Infection 42(4), 621-627 (2014).

77 Biofire Diagnostics I. FilmArray Meningitis/Encephalitis Panel. http://filmarray.com

78 Boulware DR, Rolfes MA, Rajasingham R et al. Multisite validation of cryptococcal antigen lateral flow assay and quantification by laser thermal contrast. Emerg. Infect. Dis. 20(1), 45-53 (2014).

-• Reports the diagnostic performance of cryptococcal antigen lateral flow assay (CrAg LFA) in real world use, revealing that the CrAg LFA has the best diagnostic performance of any cryptococcal diagnostic test.

79 Kabanda T, Siedner MJ, Klausner JD, Muzoora C, Boulware DR. Point-of-care diagnosis and prognostication of cryptococcal meningitis with the cryptococcal antigen lateral flow assay on cerebrospinal fluid. Clin. Infect. Dis. 58(1), 113-116 (2014).

80 Lindsley MD, Mekha N, Baggett HC et al. Evaluation of a newly developed lateral flow immunoassay for the diagnosis of cryptococcosis. Clin. Infect. Dis. 53(4), 321-325 (2011).

81 Jarvis JN, Percival A, Bauman S et al. Evaluation of a novel point-of-care cryptococcal antigen test on serum, plasma, and urine from patients with HIV-associated cryptococcal meningitis. Clin. Infect. Dis. 53(10), 1019-1023 (2011).

82 Hansen J, Slechta ES, Gates-Hollingsworth MA et al. Largescale evaluation of the immuno-mycologics lateral flow and enzyme-linked immunoassays for detection of cryptococcal antigen in serum and cerebrospinal fluid. Clin. Vaccine Immunol. 20(1), 52-55 (2013).

83 Musubire AK, Boulware DR, Meya DB, Rhein J. Diagnosis and management of Cryptococcal relapse. J. AIDS Clin. Res. (Suppl. 3 (3)), pii: S3-S003 (2013).
84 Brouwer AE, Teparrukkul P, Pinpraphaporn S et al. Baseline correlation and comparative kinetics of cerebrospinal fluid colony-forming unit counts and antigen titers in cryptococcal meningitis. J. Infect. Dis. 192(4), 681-684 (2005).

85 Chang CC, Lim A, Omarjee $S$ et al. CryptococcosisIRIS is associated with lower Cryptococcus-specific IFN-gamma responses before antiretroviral therapy but not higher T-cell responses during therapy. J. Infect. Dis. 208(6), 898-906 (2013).

86 Wheat LJ, Kohler RB, Tewari RP, Garten M, French ML. Significance of Histoplasma antigen in the cerebrospinal fluid of patients with meningitis. Arch. Intern. Med. 149(2), 302-304 (1989).

87 Litvintseva AP, Lindsley MD, Gade L et al. Utility of (1-3)-beta-D-glucan testing for diagnostics and monitoring response to treatment during the multistate outbreak of fungal meningitis and other infections. Clin. Infect. Dis. 58(5), 622-630 (2014).

88 Mikulska M, Furfaro E, Del Bono V et al. (1-3)-beta-Dglucan in cerebrospinal fluid is useful for the diagnosis of central nervous system fungal infections. Clin. Infect. Dis. 56(10), 1511-1512 (2013).

89 Marais S, Thwaites G, Schoeman JF et al. Tuberculous meningitis: a uniform case definition for use in clinical research. Lancet Infect. Dis. 10 (11), 803-812 (2010).

90 Patel VB, Singh R, Connolly C et al. Comparison of a clinical prediction rule and a LAM antigen-detection assay for the rapid diagnosis of TBM in a high HIV prevalence setting. PLoS ONE 5(12), e15664 (2010).

91 Ho J, Marais BJ, Gilbert GL, Ralph AP. Diagnosing tuberculous meningitis - have we made any progress? Trop. Med. Int. Health 18(6), 783-793 (2013).

92 Feng GD, Shi M, Ma L et al. Diagnostic Accuracy of intracellular mycobacterium tuberculosis detection for tuberculous meningitis. Am. J. Respir. Crit. Care Med.189(4), 475-481 (2014).

93 Huang Z, Xiong G, Luo Q et al. Evaluation of the performance of the microscopic observation drug susceptibility assay for diagnosis of extrapulmonary tuberculosis in China: a preliminary study. Respirology 19(1), 132-137 (2014).

94 Caws M, Dang TM, Torok E et al. Evaluation of the MODS culture technique for the diagnosis of tuberculous meningitis. PLoS ONE 2(11), e1173 (2007).

95 Xu HB, Jiang RH, Li L, Sha W, Xiao HP. Diagnostic value of adenosine deaminase in cerebrospinal fluid for tuberculous meningitis: a meta-analysis. Int. J. Tuberc. Lung Dis. 14(11), 1382-1387 (2010).

96 Park KH, Cho OH, Lee EM, et al. T-cell-based assays on cerebrospinal fluid andPBMCs for rapid diagnosis of TB meningitis in non-HIV patients. Eur. Resp. J.. 39(3), 768-770 (2012).

97 Kim SH, Cho OH, Park SJ et al. Rapid diagnosis of tuberculous meningitis by $\mathrm{T}$ cell-based assays on peripheral blood and cerebrospinal fluid mononuclear cells. Clin. Infect. Dis. 50(10), 1349-1358 (2010). 
Pingh R, Connolly C et al. Cerebrospinal T-cell responses aid in the diagnosis of tuberculous meningitis in a human immunodeficiency virus- and tuberculosis-endemic population. Am. J. Respir. Crit. Care Med. 182(4), 569-577 (2010).

99 Sardella IG, Singh M, Kumpfer S, Heringer RR, Saad MH, Sohler MP. Evaluation of Lionex TB kits and mycobacterial antigens for $\operatorname{IgG}$ and $\operatorname{Ig} A$ detection in cerebrospinal fluid from tuberculosis meningitis patients. Mem. Inst. Oswaldo Cruz105(5), 722-728 (2010).

100 Pai M, Flores LL, Pai N, Hubbard A, Riley LW, Colford JM Jr. Diagnostic accuracy of nucleic acid amplification tests for tuberculous meningitis: a systematic review and metaanalysis. Lancet Infect. Dis. 3(10), 633-643 (2003).

101 Solomons RS, van Elsland SL, Visser DH et al. Commercial nucleic acid amplification tests in tuberculous meningitis-a meta-analysis. Diagn. Microbiol. Infect. Dis.78(4), 398-403 (2014).

102 Nagdev KJ, Kashyap RS, Parida MM et al. Loop-mediated isothermal amplification for rapid and reliable diagnosis of tuberculous meningitis. J. Clin. Microbiol. 49(5), 1861-1865 (2011).

103 Tortoli E, Russo C, Piersimoni C et al. Clinical validation of Xpert MTB/RIF for the diagnosis of extrapulmonary tuberculosis. Eur. Respir. J. 40(2), 442-447 (2012).

104 Causse M, Ruiz P, Gutierrez-Aroca JB, Casal M. Comparison of two molecular methods for rapid diagnosis of extrapulmonary tuberculosis. J. Clin. Microbiol. 49(8), 3065-3067 (2011).

105 Vadwai V, Boehme C, Nabeta P, Shetty A, Alland D, Rodrigues C. Xpert MTB/RIF: a new pillar in diagnosis of extrapulmonary tuberculosis? J. Clin. Microbiol. 49(7), 2540-2545 (2011).

106 Boulware DR. Utility of the Xpert MTB/RIF assay for diagnosis of tuberculous meningitis. PLoS Med. 10(10), e1001537 (2013).

107 Viallon A, Zeni F, Lambert C et al. High sensitivity and specificity of serum procalcitonin levels in adults with bacterial meningitis. Clin. Infect. Dis. 28(6), 1313-1316 (1999).

108 Boisier P, Mahamane AE, Hamidou AA et al. Field evaluation of rapid diagnostic tests for meningococcal meningitis in Niger. Trop. Med. Int. Health 14(1), 111-117 (2009).

109 Moisi JC, Saha SK, Falade AG et al. Enhanced diagnosis of pneumococcal meningitis with use of the Binax NOW immunochromatographic test of Streptococcus pneumoniae antigen: a multisite study. Clin. Infect. Dis. 48(Suppl. 2), S49-S56 (2009).

110 Rose AM, Mueller JE, Gerstl S et al. Meningitis dipstick rapid test: evaluating diagnostic performance during an urban Neisseria meningitidis serogroup A outbreak, Burkina Faso, 2007. PLoS ONE 5(6), e11086 (2010).

111 Sakushima K, Hayashino Y, Kawaguchi T, Jackson JL, Fukuhara S. Diagnostic accuracy of cerebrospinal fluid lactate for differentiating bacterial meningitis from aseptic meningitis: a meta-analysis. J. Infect. 62(4), 255-262 (2011).

112 Srinivasan L, Pisapia JM, Shah SS, Halpern CH, Harris MC. Can broad-range $16 S$ ribosomal ribonucleic acid gene polymerase chain reactions improve the diagnosis of bacterial meningitis? A systematic review and meta-analysis. Ann. Emerg. Med. 60(5), 609-620 e602 (2012).

113 Kim DW, Kilgore PE, Kim EJ, Kim SA, Anh DD, Seki M. Loop-mediated isothermal amplification assay for detection of Haemophilus influenzae type b in cerebrospinal fluid. J. Clin. Microbiol. 49(10), 3621-3626 (2011).

114 Kim DW, Kilgore PE, Kim EJ et al. The enhanced pneumococcal LAMP assay: a clinical tool for the diagnosis of meningitis due to Streptococcus pneumoniae. PLoS ONE 7(8), e42954 (2012).

115 Meyler KL, Meehan M, Bennett D, Cunney R, Cafferkey M. Development of a diagnostic real-time polymerase chain reaction assay for the detection of invasive Haemophilus influenzae in clinical samples. Diagn. Microbiol. Infect. Dis. 74(4), 356-362 (2012).

116 Le Monnier A, Abachin E, Beretti JL, Berche P, Kayal S. Diagnosis of Listeria monocytogenes meningoencephalitis by real-time PCR for the hly gene. J. Clin. Microbiol. 49(11), 3917-3923 (2011).

117 Volle R, Nourrisson C, Mirand A et al. Quantitative realtime RT-PCR assay for research studies on enterovirus infections in the central nervous system. J. Virol. Meth. 185(1), 142-148 (2012).

118 Ninove L, Nougairede A, Gazin C et al. Comparative detection of enterovirus RNA in cerebrospinal fluid: GeneXpert system vs. real-time RT-PCR assay. Clin. Microbiol. Infect. 17(12), 1890-1894 (2011).

11 Zarrouk V, Leflon-Guibout V, Robineaux S et al. Broadrange $16 S$ rRNA PCR with cerebrospinal fluid may be unreliable for management of postoperative aseptic meningitis. J. Clin. Microbiol. 48(9), 3331-3333 (2010). 